\title{
EFFECTS AND UNDERLYING MECHANISM OF 5-LIPOXYGENASE INHIBITOR (ZILEUTON) ON MICE DEPRESSIVE-LIKE BEHAVIOR
}

\author{
SAPTARSHI PANIGRAHI ${ }^{*}$, SOMNATH SURAI ${ }^{2}$, HAO HONG $^{1}$
}

${ }^{1}$ Department of Pharmacology, Key Laboratory of Neuropsychiatric Diseases, China Pharmaceutical University, Nanjing 210009, China. ${ }^{2}$ Department of Pharmaceutics, Key Laboratory of Natural Medicines, China Pharmaceutical University, Nanjing 210009, China.

Email: saptarshi@stu.cpu.edu.cn

Received: 12 January 2020, Revised and Accepted: 12 February 2020

\section{ABSTRACT}

Objective: Treatment experiment was conducted to investigate the effectiveness and mechanism of the action of zileuton in corticosteroid-induced depressive mice model through neuroinflammation.

Methods: The mice were randomly separated into four groups: (Veh+Veh), (Corticosteroid+Veh), (Corticosteroid+ZIL50), and (Corticosteroid+ZIL100). Intraperitoneal injection of corticosterone (CORT) $(20 \mathrm{mg} / \mathrm{kg}$ for 6 weeks) was used in the mice to induce depression and neuroinflammation diverse from the Veh+Veh group, which was injected only physiological saline. The drug-treated groups (Corticosteroid+ZIL50 and Corticosteroid+ZIL100) were orally administered with the mentioned doses of zileuton. After confirming the effectiveness of zileuton through the behavioral tests, the mechanism of the action of the drug was explored through a set of biochemical assays.

Results: Zileuton $(50 / 100 \mathrm{mg} / \mathrm{kg}$ ) administration improved the performance of the mice in the behavioral experiments (p<0.05 or 0.01 ). Immunohistochemistry detection of Iba1+ revealed over activation of microglial cells in the corticosteroid-treated mice which was suppressed by the zileuton (50 or $100 \mathrm{mg} / \mathrm{kg}$ [p<0.05 or 0.01]). Through Western blotting tests, it had been found that CORT (i.p.) administration led to the increment of the protein 5-Lipoxygenase in the mouse hippocampus associated with neuroinflammation, which was decreased significantly by zileuton ( $\mathrm{p}<0.05$ or 0.01 ). Level of tumor necrosis factor-alpha, interleukin-1 beta, nuclear factor kappa B p65 protein (for neuroinflammation), Bax, and cleaved caspase-3 and TUNEL assay increased, and Bcl-2 expression decreased in the CORT-induced depressive mice. These were significantly reversed by zileuton (50 or $100 \mathrm{mg} / \mathrm{kg}[\mathrm{p}<0.05$ or 0.01$]$ ).

Conclusion: It can be concluded that selective 5-lipoxygenase inhibitor zileuton can efficiently inhibit the depressive-like behavior/activity in CORT-induced depressive mouse model. Moreover, the underlying mechanism may be the inhibition of hippocampal neuroinflammation and apoptosis.

Keywords: Depression, Zileuton, 5-Lipoxygenase, Neuroinflammation, Apoptosis.

(c) 2020 The Authors. Published by Innovare Academic Sciences Pvt Ltd. This is an open access article under the CC BY license (http://creativecommons. org/licenses/by/4. 0/) DOI: http://dx.doi.org/10.22159/ajpcr.2020.v13i3.37106

\section{INTRODUCTION}

Major depression and mania are two extremes of emotional disorders, which refer to the pathophysiological changes in mood state [1]. Depression disorder is a severe psychiatric abnormality characterized by a diffusive and chronic low mood that is accompanied by low self-esteem, psychomotor retardation or agitation, change in appetite, and an absence of interest or usually enjoyable pleasant attack [2]. Still now, the pathological mechanism of depression has not been well defined. Decreases of monoamine deficiency, the hypothalamic-pituitary-adrenal (HPA) axis hyperactivity, and neurotrophin are involved in the pathophysiology of depression [3]

Chronic stress leads to the regulation of HPA axis within the neuroendocrine system, and it was observed that the level of corticosterone (CORT) in the cycle disrupted the circadian regulation of CORT secretion and the glucocorticoid (GC) receptor negative recompose circuit [4]. Proved that, chronic stress could cause an imbalance in the HPA axis in neuroendocrine system. In patients with depression, hippocampal feedback was impaired, leading to excessive activity of HPA axis and elevated levels of humeral corticosteroids [5,6]. As a result, Cushing's disease with patients or those receiving long-term pharmacotherapy with GC shows an exceptionally high rate of depression [7]. Stimulation and continued actions of the HPA axis are attenuated through the adverse feedback circulating GC following exogenous CORT administration, and this is generally related to the improvement of psychosomatic disorders, which lead to severe changes in indicative or consistent emotional behavior accompanied by depressive-like symptoms [8,9]. HPA axis is activating by high dose of CORT administration, will increment depressive behavior in rodents, as held by a significantly diminish in sucrose consumption [8].

Arachidonic acid (AA) metabolized into inflammatory molecules called as leukotrienes (LTs) that have been metabolized by 5-lipoxygenase (5-LOX) inhibitor, which are capable mediators of several inflammatory and vascular diseases.

Zileuton attenuates brain inflammation in cerebral ischemia by inhibiting the nuclear factor-kappa B (NF- $\mathrm{B})$ p 65 and downstream inflammatory mediators. However, it is important to further discover the potential mechanism of zileuton's neuroprotection against central nervous system (CNS) disorders.

Given this background, in this research work, we focused to give a glimpse the effects of 5-LOX drug zileuton $(50 \mathrm{mg} / \mathrm{kg}$ and $100 \mathrm{mg} / \mathrm{kg}$ ) treatment on the tail suspension test (TST), forced swimming test (FST), novelty suppression feeding test (NSFT), and open-field test (OFT) in mice that show repetition of exposure to CORT. Nowadays, many evidence suggested that neuroinflammation is responsible for the pathophysiology of depression $[9,10]$. We can show remarkable influence in both patients suffering depression and animal model of depression in the presence of high levels of pro-inflammatory cytokines, for example, interleukin-1 beta (IL-1 $\beta$ ) and tumor necrosis factor-alpha (TNF- $\alpha)[10,11]$. These pro-inflammatory cytokines show 
an impact on the plasticity and neurotransmission, therefore, suppress the neurogenesis in the brain, and appliance of antidepressants suppresses these cytokines activation. The conversion of AA to 5-hydroxyperoxyeicosatetraenoic acid is carried out in the presence of a pro-inflammatory enzyme named 5-LOX and afterward the catalysis, it also produces hydroxyeicosatetraenoic acid (5-HETE). Therefore, it metabolized in several LTs [12]. 5-LOX and the LTs in the CNS perform both neuromodulatory and neuroendocrine effects [13] and lead to inflammatory response characterized by the increments of IL-1 $\beta$, TNF- $\alpha$, and NF- $\kappa$ B. Nowadays, a mass of researchers focused on 5-LOX. 5-LOX is responsible for the various type of CNS damage such as cerebral ischemia, cognitive deficit, traumatic brain injury, and anxiety by implicating its novel pathophysiological role [14-16]. Therefore, the relationship and the mechanism between 5-LOX and depressive-like behaviors need to be clarified. During this study, we first observed whether 5-LOX inhibitor zileuton prevents depressive behaviors and neuroinflammatory responses in CORT (corticosteroid)-induced mice model [17].

Furthermore, we tend to additionally evaluate whether the behavioral antidepressant-like effects of zileuton associated with alterations in hippocampal cell proliferation and neuronal commitment, as well as astrocytic hyperactivation.

\section{MATERIALS, EQUIPMENT, AND METHODS}

Materials

The pure drug zileuton was generously obtained from Dalian Meilun Biological Co., Ltd., China, CORT (corticosteroid) was purchased from Dalian Meilun Biological Co., Ltd., China, streptavidin-biotin complex (SABC) immunohistochemistry (IHC) kit was purchased from Wuhan Boster Biological Technology, Ltd., China. Trizol reagents and bovine serum albumin were purchased from Nanjing SunShine Biotechnology Co., Ltd., China; Western blot markers were obtained from Thermo Scientific, USA. Chemiluminescence detection reagents were purchased from Tanon Science and Technology Co., Ltd., China. Caspase-3 rabbit monoclonal antibody, Bcl-2 rabbit monoclonal antibody, and Bax rabbit monoclonal antibody were purchased from Cell Signaling Technology Ltd., USA.

\section{Equipment}

Tanon 4200 chemiluminescent protein (Tanon Science and Technology Co., Ltd., China). XW-80A type vortex mixer (Shanghai Huxi Analysis Instrument Factory Co., Ltd., China), CM1950 cryostat (LEICA, Germany), SR-5 stereotaxic instruments (Narishige, Japan).

\section{Animals}

Institute of Cancer Research mice were used for this experiment, took 12 mice in each group. All experiments were conveyed according to NIH guide for the care, and animal care committee in China Pharmaceutical University approved the use of laboratory animal (NIH publications No. 80-23, received, 1996) and the procedures. All animals were placed on a 12-h dark/light cycle with free access to water and standard chow and adapted for 1 week before the start of the experiment.
The experimental design is illustrated in Fig. 1. Animals were divided into four groups: Vehicle+Vehicle normal physiological saline (Veh+Veh), corticosteroid $20 \mathrm{mg} / \mathrm{kg}+$ Vehicle (CORT+Veh), corticosteroid $20 \mathrm{mg}$ / kg+zileuton $50 \mathrm{mg} / \mathrm{kg}$ (CORT+ZIL50), and corticosteroid $20 \mathrm{mg} /$ kg+zileuton $100 \mathrm{mg} / \mathrm{kg}$ (CORT+ZIL100). CORT administers by intraperitoneal (i.p) route and Zileuton administer by intragastric (i.g.). Every day CORT [ $20 \mathrm{mg} / \mathrm{kg}$ body weight $\}, 5 \mathrm{ml} / \mathrm{kg} 0.1 \mathrm{ml} / 20 \mathrm{~g}$ of body weight (dissolve in dimethyl sulfoxide $0.1 \%$, Tween-80 [0.1\%] and require volume makeup by physiological saline)] was intraperitonially administration in mice. After 3 weeks of CORT administration, zileuton (50 mg/kg or $100 \mathrm{mg} / \mathrm{kg}$ ), $0.2 \mathrm{ml} / 10 \mathrm{~g}$ of body weight (dissolved in methanol [0.5\% methanol] and physiological saline), was orally given in mice daily by intragastric route (i.g.). After 21 days for behavioural tests were performed. After the behavioral tests, the mice were sacrificed by cervical dislocation and the full brain was extracted for IHC and Western blotting (WB).

\section{Behavior tests}

FST

The FST was performed [18]. In short, separately placed the mice in a glass cylinder (diameter $19 \mathrm{~cm}$, height $25 \mathrm{~cm}$ ) containing water $\left(25 \pm 1^{\circ} \mathrm{C}\right)$ to a depth of $13 \mathrm{~cm}$ and allowed to swim for $6 \mathrm{~min}$. Record the behavior of the mice and explored by TSE behavioral software. After a 6 min test, removed the mouse from the tank and thoroughly dried with dry cloth then returned to the colony room in their home cage. Change the tank's water after each swim session. Judged the immobility time as the absence of active, unwanted behavior, such as jumping, swimming, rearing or diving. Measured the total immobility time during the final $4 \mathrm{~min}$ of a $6 \mathrm{~min}$ test season by an observer blind to the treatment conditions.

\section{TST}

TST was performed [19]. After FST, mice were conducted $24 \mathrm{~h}$. Shortly, moved the mice from housing room to the testing room in their home cages, at least $1 \mathrm{~h}$ before testing to allow for adapt to the new environment. During the dark period of the circadian cycle, mice were tested. Each mouse was hanged by his or her tail with adhesive tape to the hook in the soundproof box. The total immobility period during 6 min test was explored by ANY-MAZE software. The immobility period during initial 2 min of the 6 min task was discounted while the last 4 min task was explored statistically.

OFT

The OFT was performed [20]. The mice were conducted $24 \mathrm{~h}$ after TST. The open field contained $(40 \times 40 \times 38 \mathrm{~cm})$ square arena with clean Plexiglas wall and floor. At first, mouse was placed in one corner of the open space and during a $5 \mathrm{~min}$ test, session allowed to move arena freely. Measured peripheral and central activities using a computerassisted activity system with software to easily the data collection and analysis.

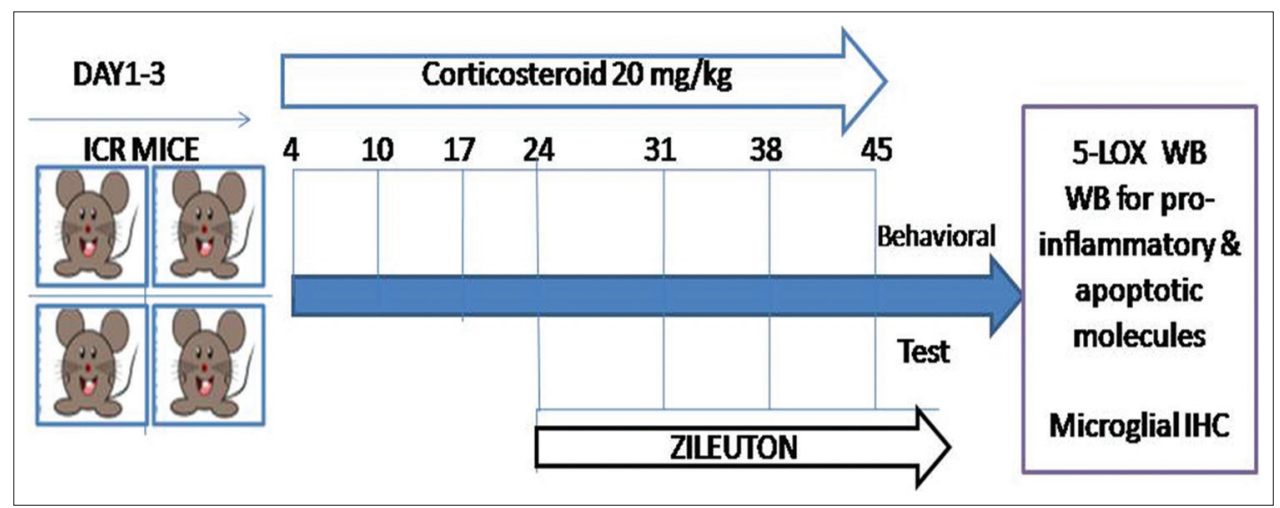

Fig. 1: Study design and animal treatments 
NSFT

After habituation in the testing room, mice were subjected to the NSFT test [21]. The testing instrument consists of a plastic box $(50 \times 50 \times 20 \mathrm{~cm})$, covered by wooden bed $2 \mathrm{~cm}$. Twenty-four hours before this behavioral test, all food was removed from their cage. At testing time, a single pellet of food was placed on a white paper platform in the center of the testing box. The mouse has placed in the center of the box. The mouse was placed in the corner of the box and instantly started the stopwatch. The latency to eat (it means the mouse sitting on its haunches and biting the pellet with the use of forepaws) was recorded.

\section{Tissue preparation and immunohistochemical analyses}

Tissue preparation, at first anesthetized the mice and perfused transcardially with $0.1 \mathrm{M}$ phosphate-buffered saline (PBS) (pH-7.4), contains $4 \%$ paraformaldehyde and $5 \mathrm{U} / \mathrm{ml}$ heparin. Then, the brain was collected and fixed in $4 \%$ paraformaldehyde for $18-20 \mathrm{~h}$ followed by $30 \%$ sucrose solution for $24 \mathrm{~h}$. After then, the brain was dissected and embedded into optimal cutting temperature compound on dry ice and cryosectioned at $30 \mu \mathrm{m}$. Following the manufacturer's instructions, immunohistochemical staining was performed using SABC IHC kit. After washing, the section with $0.1 \mathrm{M}$ PBS solution heated the sections on water bath for $4 \mathrm{~h}$ in $0.3 \%$ Triton X-100 at $60^{\circ} \mathrm{C}$. Then again washed the section and treated with $3 \% \mathrm{H}_{2} \mathrm{O}_{2}$ at normal room temperature for $10 \mathrm{~min}$ and washed with PBS for $3 \times 5$ min followed by blocking $5 \%$ BSA for $30 \mathrm{~min}$. After then, the sections were incubated overnight at $4^{\circ} \mathrm{C}$ with primary antibody for Iba 1 (rabbit immunoglobulin G [IgG], 1:1000) diluted in $5 \%$ BSA. Next day, washed the sections in PBS for $3 \times 5$ min at room temperature and incubated with biotinylated mouse anti-rabbit IgG for $20 \mathrm{~min}$. After then, again rewashed in PBS $\left(3 \times 5 \mathrm{~min}, 37^{\circ} \mathrm{C}\right)$ and incubated with $\mathrm{SABC}$ at $37^{\circ} \mathrm{C}$ for $20 \mathrm{~min}$. Again, sections were washed in $0.1 \mathrm{M}$ PBS for $4 \times 5 \mathrm{~min}$ and mounted on the glass slides. Then added the diaminobenzidine followed by gradient dehydration ([1] $70 \%$ ethanol for $5 \mathrm{~min}$, [2] 95\% ethanol for $5 \mathrm{~min}$, [3] $100 \%$ ethanol for $2 \times 5 \mathrm{~min}$, and [4] xylene for $2 \times 5 \mathrm{~min}$ ). Next, sections were covered with DPX mounting solution and cover glass. At last, photomicrographs were obtained using a Nikon DS-Fi2 camera connected to a Nikon Eclipse Ti microscope and analyzed by the Image-Pro Plus software.

\section{Total protein and nuclear protein extraction}

Homogenized the mouse hippocampus in an ice-cold radioimmunoprecipitation assay buffer, it contains $0.1 \%$ phenylmethylsulfonyl fluoride (PMSF). The homogenate was centrifuged at 12,000 g for $15 \mathrm{~min}$ and collected the supernatant. Total protein concentration was determined. The supernatant was used to determine using the bicinchoninic acid protein kit and stored at $-20^{\circ} \mathrm{C}$.

Nucleoprotein extraction kit was used for nuclear extraction. Shortly, chopped the mouse hippocampus into small pieces, then homogenized in the ice-cold hypotonic buffer, contains $1 \%$ PMSF, $0.5 \%$ phosphate inhibitor, $0.1 \%$ DL-Dithiothreitol (DDT) and then centrifuged at $4{ }^{\circ} \mathrm{C}$ $3000 \mathrm{~g}$ for $5 \mathrm{~min}$. Then washed the precipitate with hypotonic buffer solution and centrifuged at $4{ }^{\circ} \mathrm{C}, 5000 \mathrm{~g}$ for $5 \mathrm{~min}$. Finally, $0.2 \%$ lysis buffer containing $1 \%$ PMSF, $0.1 \%$ DDT, and $0.5 \%$ phosphatase buffer was added into the precipitate, cooled for $20 \mathrm{~min}$, and centrifuged at $4^{\circ} \mathrm{C}, 15,000 \mathrm{~g}$ for $10 \mathrm{~min}$. Subjected the supernatant nuclear extract was detected by WB assay for NF-kB p65 and histone $\mathrm{H} 3$ using as the control.

\section{Western blot analysis}

The sample was run to evaluate the protein and isolate the protein bands by sodium dodecyl sulfate-polyacrylamide gel electrophoresis. Then transferred the bands onto polyvinylidene difluoride membrane and blocked with $5 \%$ skim milk prepared in Tris-buffer saline solution. Membranes were incubated at $4{ }^{\circ} \mathrm{C}$ overnight with the respective primary antibody for 5 -LOX (1:1000), IL-1 $\beta$ (1:500), TNF- $\alpha$ (1:500), Caspase-3 (1:1000), Bcl-2 (1:200), and Bax (1:1000); $\beta$-actin (1:3000) was used as control.

For NF-kB p65 (1:1000), histone H3 (1:1000) loading control. After the overnight incubation, membranes were washed with Tris buffer saline - Tween 20 and incubated for $2 \mathrm{~h}$ at room temperature, with a horseradish peroxidase-conjugated secondary antibody (1:50001:10000). Finally, visualized the antibody reactive bands using enhanced chemiluminescence detector reagents (1:1) by gel imaging system.

\section{Statistical analysis}

Data shown are expressed as mean \pm standard error of the mean using analysis of variance (ANOVA) software to analyze the behavioral tests (TST, OFT, FST, and NSFT). All other data were analyzed by one-way ANOVA for various comparisons followed by Dennett's post hoc analyzer. All analyses were carried out using the SPSS 22.0. Considered that, $\mathrm{p}<0.05$ was statistically significantly difference between the groups.

\section{RESULTS}

CORT-induced depressive-related behaviors are ameliorated by zileuton

To evaluate that, whether 5-LOX inhibition prevents CORT-induced depression-related behaviors, we treated the mice using a specific 5-LOX inhibitor zileuton and performed different behavior tests. Hope that the mice reveal to CORT showed an increase of immobility time in the TST (Fig. 2a, F(3,32)=8.183, p<0.01). Treatment with zileuton $(50 \mathrm{mg} / \mathrm{kg}$ or $100 \mathrm{mg} / \mathrm{kg}$ ) significantly reduced the immobility time in the TST (Fig. 2a, CORT+Zil50 and CORT+Zil100: p<0.01) compare to the CORT-treated group. Similarly, same result was obtained in the FST. In contrast with the Veh+Veh group, mice treated with CORT expend longer immobility time (Fig. $2 \mathrm{~b}, \mathrm{~F}(3,32)=4.888$, $\mathrm{p}<0.01$ ), and this was minimized by zileuton treatment $(50 \mathrm{mg} / \mathrm{kg}$ or $100 \mathrm{mg} / \mathrm{kg}$ ) (Fig. 2b, CORT+Zil50: $\mathrm{p}<0.05$ and CORT+Zil100: $\mathrm{p}<0.01$ ). In addition, the anxiety-related behaviors were assessed employed NSFT, in which mice displayed an increase in the latency to feed in the novel environment (Fig. 2c, F(3,32)=7.218, p<0.01). While no differences observed in home cage consumption index (Fig. 2d, $F(3,32)=0.327$, $\mathrm{p}>0.05$ ) after CORT injection, zileuton treatment $(50 \mathrm{mg} / \mathrm{kg}$ or $100 \mathrm{mg} /$ $\mathrm{kg}$ ) suppressed the latency to feed in CORT-induced mice (Fig. 2c, CORT+Zil50 and CORT+Zil100: $\mathrm{p}<0.05$ ). The locomotor activities were observed in the OFT, and there was no difference between all groups (Fig. 2e, CORT+Zil50 and CORT+Zil100: p>0.05). Furthermore, our studies also expressed that zileuton $(50 \mathrm{mg} / \mathrm{kg}$ and $100 \mathrm{mg} / \mathrm{kg}$ ) administration diminished depressive behavior in compared to CORTinduced depressive mice model. Taken together, hippocampal 5-LOX inhibitor zileuton may significantly prevent CORT-induced depressivelike behaviors.

\section{Zileuton blocks CORT-induced microglial activation}

It informed that CORT activates the mediated inflammatory response through microglia, whose changes are characterized by improved cell numbers and conformational changes, as well as size enlargement and thicker processes [22]. To study the effects of hippocampal 5-LOX enzyme on microglia, we detected the activation levels of microglia by immunohistochemical method. As shown in figure, the number of IBA1 positive cells in the hippocampus of CORT-induced mice was significantly prolonged (Fig. 3a, $\mathrm{F}(3,12)=13.115$, $\mathrm{p}<0.01$ ) compared to the Veh+Veh group, while zileuton $(50 \mathrm{mg} / \mathrm{kg}$ or $100 \mathrm{mg} / \mathrm{kg}$ ) significantly decreased IBA1 staining cells (Fig. 3b CORT+Zil50: $\mathrm{p}<0.05$ and CORT+Zil100: $\mathrm{p}<0.01$ ).

Zileuton prevents CORT-activated NF- $\mathrm{\kappa B}$ signaling and production of pro-inflammatory cytokines

Evidence exhibits that 5-LOX regulates inflammatory response by controlling NF- $\kappa B$ pathway [23], and CORT activated the NF- $\kappa$ B pathway by triggering the nuclear translocation of the p65 subunit. Herein, we are curious about whether 5-LOX involved in the CORT-activated NF- $\mathrm{KB}$ pathway. Actively, after the 5 -LOX inhibitor, zileuton $(50 \mathrm{mg} / \mathrm{kg}$ or $100 \mathrm{mg} / \mathrm{kg}$ ), treatment in the hippocampus was significantly inhibited by NF-KB signaling (Fig. 4a, F(3,32)=11.858, $\mathrm{p}<0.01$ ), which can block the expression of hippocampal 5-LOX (Fig. 4b, CORT+Zil50: $\mathrm{p}<0.05$ and CORT+Zil100: $\mathrm{p}<0.01$ ).

Activated microglia and NF- $\mathrm{\kappa B}$ pathway may regulate various proinflammatory cytokines involved in the onset of depression [24] to 


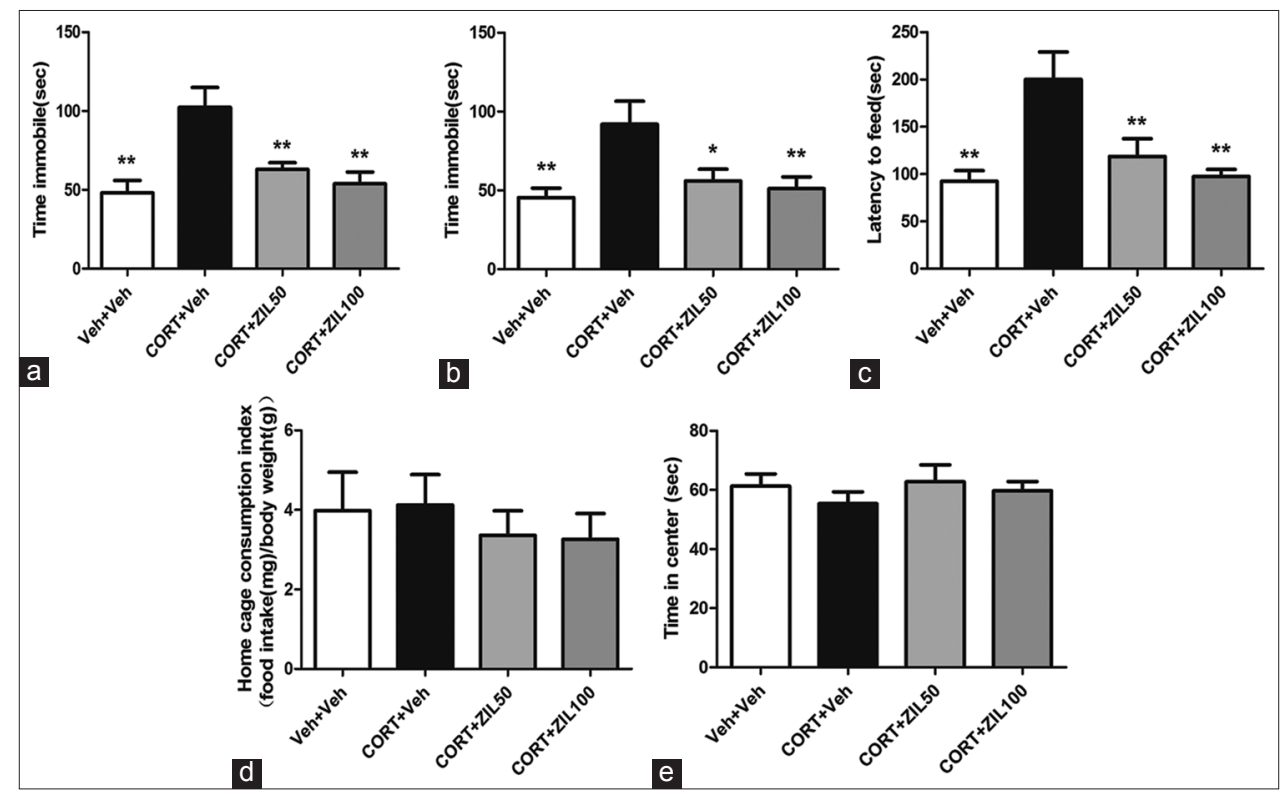

Fig. 2: Zileuton prevents corticosterone (CORT)-induced depression-related behaviors. (a) (Tail suspension test) immobility time, (b) (forced swimming test) immobility time, (c) latency to feed, (d) (novelty suppression feeding test) home cage consumption index and (e) (open-field test) line crossings were shown. Mice were injected with CORT (20 mg/kg, i.p.), for 6 weeks period; 2 h later, they were treated drugs, respectively, once daily for the past 3 weeks and then subjected all mice for behavior tests. The data are indicated as mean \pm standard error of the mean $(n=9) .{ }^{*} \mathrm{p}<0.05,{ }^{* *} \mathrm{p}<0.01$ versus CORT+Veh group
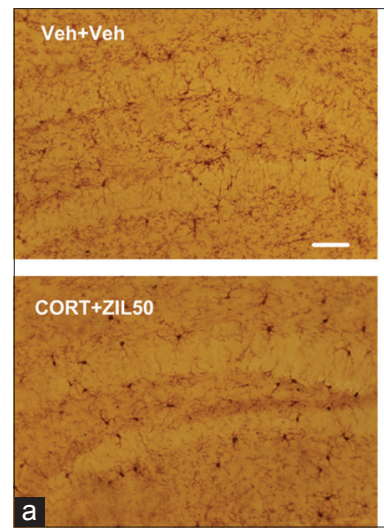
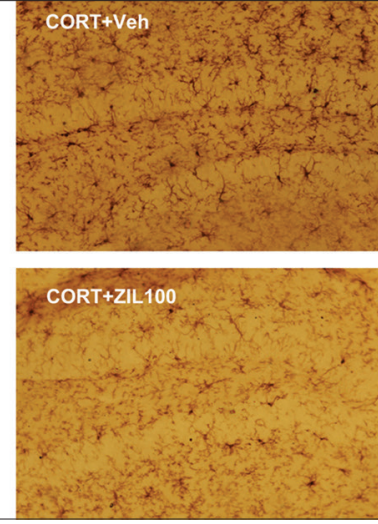

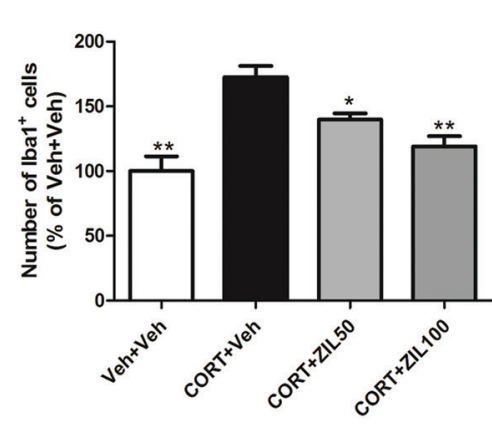

b

Fig. 3: Zileuton blocks corticosterone (CORT)-induced microglial activation. Sacrificed the mice and sections the mice brains for immunohistochemical staining for the microglial marker Iba1. (a) Representative microphotographs show Iba1 immunostained microglia of the mouse hippocampus. (b) The number of Iba1 antibody-stained microglia was normalized in the same corresponding area, as the ratio (in \%) of the Veh+Veh group is shown. Administration of CORT and drugs was the same as that in Fig. 2. Data shown are revealed as mean \pm standard error of the mean $(n=4) .{ }^{*}<<0.05,{ }^{* *} p<0.01$ versus CORT+Veh group. These data suggest that 5 -Lipoxygenase inhibitor zileuton blocks CORT-induced microglial activation

investigate the effect of zileuton on the neuroinflammatory process induced by CORT.

The expression of pro-inflammatory cytokines such as IL-1 $\beta$ and TNF- $\alpha$ was detected by western blot. As shown in figure, CORT expression significantly enhanced the generations of TNF- $\alpha$ and IL-1 $\beta$ in the hippocampus (Fig. 4c, F(3,12)=13.873, p <0.01; Fig. 4e, F(3,12)=14.683, $\mathrm{p}<0.01)$, whereas zileuton $(50 \mathrm{mg} / \mathrm{kg}$ or $100 \mathrm{mg} / \mathrm{kg}$ ) suppressed the production of TNF- $\alpha$ and IL- $1 \beta$ (Fig. $4 \mathrm{~d}$ and f CORT +Zil50: $p<0.05$ and CORT+Zil100: $\mathrm{p}<0.01$ ). These results suggest that 5-LOX inhibitor prevents the production of pro-inflammatory cytokines induced by CORT.

Zileuton prevents neuronal apoptosis

Evidence has shown that 5-LOX decreases pro-apoptotic molecules such as cleaved caspase-3, and Bax and TUNEL in the mouse hippocampus while the level of the anti-apoptotic protein Bcl-2 was increased. Figure (Fig. 5a, $\mathrm{F}(3,12)=9.625, \mathrm{p}<0.01$ ) shown that zileuton (more $100 \mathrm{mg} / \mathrm{kg}$ than $50 \mathrm{mg} / \mathrm{kg}$ dose) decreases cleaved caspase-3 in compared to CORT-induced mice model (Fig. $5 \mathrm{~b}$ CORT+Zil50: $<<0.05$ and CORT+Zil100: p<0.01). Similarly, zileuton decreases Bcl-2/Bax ration in comparison to CORT-induced mice model (Fig. 5c, $F(3,12)=10.393$, $\mathrm{p}<0.01$ ) (Fig. 5d CORT+Zil50: $\mathrm{p}<0.05$ and CORT+Zil100: $\mathrm{p}<0.01$ ). In immunofluorescence assay, zileuton decreases neuronal apoptosis in TUNEL-positive cells ratio in mouse hippocampus (Fig. 5e, $\mathrm{F}(3,12)=9.806$, $\mathrm{p}<0.01)$ (Fig. 5 f CORT + Zil50 and CORT+Zil100: $\mathrm{p}<0.01$ ).

\section{DISCUSSION}

Through the present study provides evidence that the neuroprotective effect of zileuton has shown in CORT-induced depressive mice model through modulating loss of behavioral activities, activation of microglia, neuroinflammation, and cell apoptosis. Specifically, CORT led to the significant increase of hippocampal 5-LOX protein, produced several 


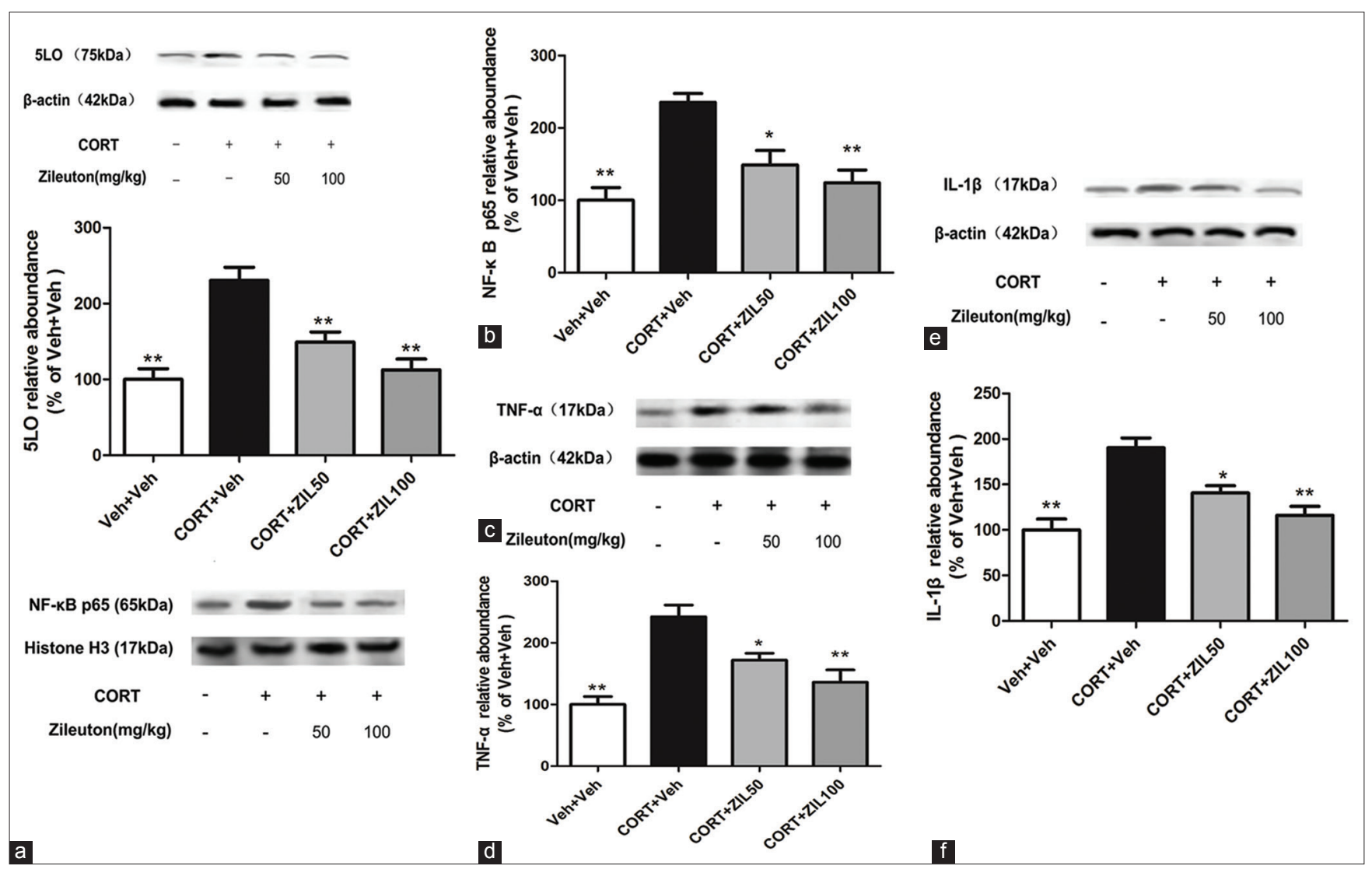

Fig. 4: Zileuton prevents corticosterone (CORT)-activated nuclear factor kappa B (NF- $\mathrm{B}$ ) signaling and production of pro-inflammatory cytokines. The protein expression of hippocampal nuclear $(\mathrm{a}, \mathrm{b}) \mathrm{NF- \kappa B}$ p65, (c,d) tumor necrosis factor-alpha, $(\mathrm{e}, \mathrm{f})$ interleukin 1 beta, and $\beta$-actin or histone $\mathrm{H} 3$ as loading control were examined by Western blot using respective antibodies (1:1000). Quantification expressed as the ratio (in \%) of Veh+Veh group is shown. Administration of CORT and drugs was the same. The data are revealed as mean \pm standard error of the mean $(n=4) .{ }^{*} p<0.05,{ }^{* *} p<0.01$ versus CORT+Veh group

behavioral activities including increased immobility time in the FST and TST test, and increased the latency to feed in the NSFT in mice. It was accompanied by the hippocampal inflammatory response, activated microglia, increased the expression of TNF- $\alpha$, IL- $1 \beta, N F-\kappa B ~ p 65$, increased cellular apoptosis caspase-3, Bax, TUNEL, and decreased Bcl-2. 5-LOX inhibitor drug zileuton markedly attenuated these effects by inducing CORT. These results suggesting that antidepressant effect of 5-LOX inhibitor reduced neuroinflammation. In addition, increasing evidence suggested that a strong association in-between neuroinflammation and depression, which was marked by, increased levels of pro-inflammatory cytokines in the CNSs. The 5-LOX is broadly expressed in the CNS. It localizes mainly in neuronal cells $[25,26]$. In recent study had suggested in various regions of the brain, including the hippocampus. Where its levels was increased. We first identified the expression of hippocampal 5-LOX in depressive mice model by induced CORT, which was used to model inflammation with depressive disorders.

Therefore, we found that after the administration of zileuton produced an antidepressive effect in the behavioral tests, exhibited by inhibiting the CORT stress-induced increase in immobility time in the FST and TST and to the difference in locomotor activities by observed in OFT. In addition, depression often with anxiety in patients, so we estimated the anxiety-like behavior by the selection of NSFT. Zileuton treatment significantly opposite the anxiety-like behaviors induced by CORT, characterized by reducing the increment of latency to feed by CORT. Moreover, zileuton exhibited an antidepressant effect.

Treatment with zileuton is one of the 5-LOX inhibitors, successfully attenuated histopathological and biochemical changes by induced
CORT microglial associated neuroinflammation in intraperitoneal route [24,27]. However, histological changes in microglia have considered being a pathophysiological role of depression [28]. 5-LOX effective inflammatory mediator, which plays a crucial role in the asthma patient and other inflammatory diseases $[29,30]$.

The 5-LOX inhibitor, zileuton, is a novel class of anti-asthma drugs and well tolerated in asthma patient [31,32]. 5-LOX-mediated signaling is relative to NF- $\mathrm{KB}$ pathway [33-36]. NF- $\mathrm{KB}$, an important transcription factor, regulates the expression of several pro-inflammatory cytokines such as TNF- $\alpha$ and IL-1 $\beta[37,38]$. Hence, NF- $\kappa B$ has reported mediate microglia activation and suppressing NF- $\mathrm{KB}$ transcriptional activity inhibits the production of pro-inflammatory cytokines $[39,40]$. Administration of zileuton $(50 \mathrm{mg} / \mathrm{kg}$ and $100 \mathrm{mg} / \mathrm{kg}$ ) regulated these pro-inflammatory cytokines through inhibition (TNF- $\alpha$ and IL-1 $\beta$ ) of NF- $\mathrm{KB}$ p 65 .

Evidence focuses that apoptosis as an essential faction contributing depression pathogenesis [41] not only inhibits the inflammatory reactions but also blocks the apoptotic processes as well [42].

In addition, microglia-derived TNF- $\alpha$ and IL-1 $\beta$ can mediate cell death [43]. Therefore, suppressing the NF-KB signaling and microglial activation is helpful against depression-related neuronal apoptosis. Earlier studies have shown that pro-apoptotic protein such as Bax, caspase- 3 , and antiapoptotic protein Bcl- 2 is related in depressive mice model $[37-38,41]$ and blocking NF- $\mathrm{\kappa B}$ opposite changes in depressive mice [44]

Here, this experiment increase of CORT caused increment of pro-apoptotic molecules such as caspase-3, Bax, TUNEL 


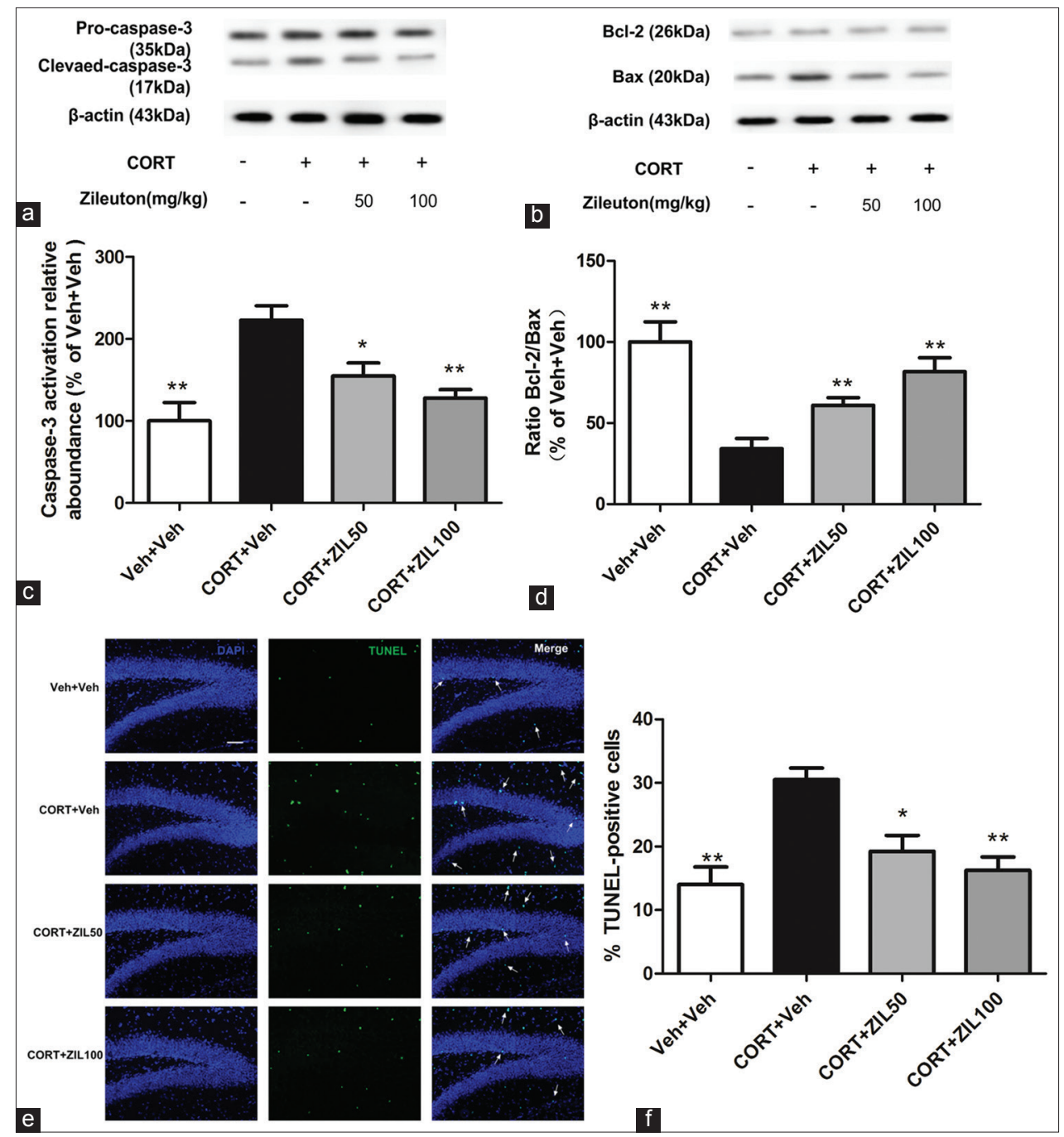

Fig. 5: Zileuton decreases the caspase 3 activation in corticosterone (CORT)-induced mice. Entire hippocampus extracts were adapted to Western blot analysis through an antibody against caspase 3 , (a,b) pro-caspase 3 and cleaved caspase 3 and (c,d) Bcl-2/Bax. Quantification of the protein levels of (b) caspase 3 and (d) Bcl-2/Bax was expressed as the ratio (in \%) of Veh+Veh group. (e,f) Entire hippocampus extracts were adapted to TUNEL staining by fluorescence microscopy. The results are revealed as mean \pm standard error of the mean $(\mathrm{n}=4) .{ }^{*} \mathrm{p}<0.05,{ }^{* *} \mathrm{p}<0.01$ versus CORT+Veh group

immunofluorescence assay, and approximately Bcl-2 reduction in the mouse hippocampus. However, the treatment of zileuton $(50 \mathrm{mg} / \mathrm{kg}$ and $100 \mathrm{mg} / \mathrm{kg}$ ) significantly gives such response in comparison to model group. Therefore, it concluded that 5-LOX could be a promising target for the treatment of depression.

\section{CONCLUSION}

The effect of 5-lipoxygenase was founded by clinical studies targeted against neuroinflammatory cascade with the synthesis pathway in the pathogenesis of depression.

However, the study was limited to usage of the research of depressive mice model, and must be needed to discover them for depression. It was research to explore by Utilization of CORT (corticosteroid) induced mouse model of depression. My research show neuroinflammation was strongly related to behavioral activities. In this research, activation of microglia was frequent. Increases the level of proinflammatory cytokines (such as TNF- $\alpha$, IL-1 $\beta$ ) and pro-apoptotic molecules (cleaved caspase- 3 and TUNEL) observed while reduces in the antiapoptotic molecule (Bcl-2) reserved in the CORT (corticosterone in an intraperitoneal injection) induced mice, possibly through the NF-кB signaling pathway.
5 -LOX inhibitor zileuton treatment, at high doses $(100 \mathrm{mg} / \mathrm{kg})$ is more than zileuton $(50 \mathrm{mg} / \mathrm{kg})$, reversed/reduced such changes and showed some outcome in the behavioral tests.

This experiment illustrates that 5-LOX enzyme as an emerging therapeutic target in depressive mouse model and motivates 5-LOX inhibitor such as Zileuton, basically used in anti-asthmatic drug, to be promoted for the treatment of depression, which can minimize the mental, clinical social and economic liability of depression.

\section{ACKNOWLEDGMENTS}

This work was supported by grants from the National Natural Science Foundation of China (81573413 and 81773714 to Hao Hong) and the Fundamental Research Funds for the Central Universities (2632017PT01). Saptarshi Panigrahi is a recipient of China Govt. Scholarship-Chinese University Program (China Scholarship Council) for foreign students at China Pharmaceutical University. Somnath Surai is a recipient of Master degree CSC scholarship at CPU.

\section{AUTHORS' CONTRIBUTIONS}

Both authors have contributed to reviewing the preparation and editing of the manuscript. 


\section{CONFLICTS OF INTEREST}

The authors declare no conflicts of interest.

\section{REFERENCES}

1. Duman RS. Pathophysiology of depression and innovative treatments: Remodeling glutamatergic synaptic connections. Dialogues Clin Neurosci 2014;16:11-27.

2. Steiner MA, Marsicano G, Nestler EJ, Holsboer F, Lutz B, Wotjak CT. Antidepressant-like behavioral effects of impaired cannabinoid receptor type 1 signaling coincide with exaggerated corticosterone secretion in mice. Psychoneuroendocrinology 2008;33:54-67.

3. Brown ES, Varghese FP, McEwen BS. Association of depression with medical illness: Does cortisol play a role? Biol Psychiatry 2004;55:1-9.

4. Wulsin AC, Herman JP, Solomon MB. Mifepristone decreases depression-like behavior and modulates neuroendocrine and central hypothalamic-pituitary-adrenocortical axis responsiveness to stress. Psychoneuroendocrinology 2010;35:1100-12

5. Sonino N, Fallo F, Fava GA. Psychosomatic aspects of Cushing's syndrome. Rev Endocr Metab Disord 2010;11:95-104.

6. Huang Z, Zhong XM, Li ZY, Feng CR, Pan AJ, Mao QQ. Curcumin reverses corticosterone-induced depressive-like behavior and decrease in brain BDNF levels in rats. Neurosci Lett 2011;493:145-8.

7. Lee B, Shim I, Lee HJ, Yang Y, Hahm DH. Effects of acupuncture on chronic corticosterone-induced depression-like behavior and expression of neuropeptide Y in the rats. Neurosci Lett 2009;453:151-6.

8. Lan R, Xiang J, Zhang Y, Wang GH, Bao J, Li WW, et al. PI3K/Akt Pathway Contributes to Neurovascular Unit Protection of Xiao-XuMing Decoction against Focal Cerebral Ischemia and Reperfusion Injury in Rats. Evid Based Complement Alternat Med 2013;2013:459467.

9. Dantzer R, O’Connor JC, Freund GG, Johnson RW, Kelley KW. From inflammation to sickness and depression: When the immune system subjugates the brain. Nat Rev Neurosci 2008;9:46-56.

10. Raison CL, Capuron L, Miller AH. Cytokines sing the blues: Inflammation and the pathogenesis of depression. Trends Immunol 2006;27:24-31.

11. Liu Y, Ho RC, Mak A. Interleukin (IL)-6, tumour necrosis factor alpha $(\mathrm{TNF}-\alpha)$ and soluble interleukin-2 receptors (sIL-2R) are elevated in patients with major depressive disorder: A meta-analysis and metaregression. J Affect Disord 2012;139:230-9.

12. Rådmark $\mathrm{O}$, Werz $\mathrm{O}$, Steinhilber D, Samuelsson B. 5-Lipoxygenase: Regulation of expression and enzyme activity. Trends Biochem Sci 2007;32:332-41.

13. Nakagawa Y, Chiba K. Role of microglial $\mathrm{m} 1 / \mathrm{m} 2$ polarization in relapse and remission of psychiatric disorders and diseases. Pharmaceuticals (Basel) 2014;7:1028-48.

14. Giannopoulos PF, Chu J, Joshi YB, Sperow M, Li JG, Kirby LG, et al. Gene knockout of 5-lipoxygenase rescues synaptic dysfunction and improves memory in the triple-transgenic model of Alzheimer's disease. Mol Psychiatry 2014;19:511-8.

15. Joshi YB, Praticò D. Knockout of 5-lipoxygenase results in agedependent anxiety-like behavior in female mice. PLoS One 2011;6:e29448.

16. Shi SS, Yang WZ, Tu XK, Wang CH, Chen CM, Chen Y. 5-Lipoxygenase inhibitor zileuton inhibits neuronal apoptosis following focal cerebral ischemia. Inflammation 2013;36:1209-17.

17. Gupta D, Radhakrishnan M, Kurhe Y. Effect of a novel 5-HT3 receptor antagonist $4 \mathrm{i}$, in corticosterone-induced depression-like behavior and oxidative stress in mice. Steroids 2015;96:95-102.

18. Porsolt RD, Martin P, Lenègre A, Fromage S, Drieu K. Effects of an extract of Ginkgo Biloba (EGB 761) on "learned helplessness" and other models of stress in rodents. Pharmacol Biochem Behav 1990;36:963-71.

19. Cryan JF, Mombereau C, Vassout A. The tail suspension test as a model for assessing antidepressant activity: Review of pharmacological and genetic studies in mice. Neurosci Biobehav Rev 2005;29:571-625.

20. Baitharu I, Jain V, Deep SN, Kumar G. Exposure to hypobaric hypoxia and reoxygenation induces transient anxiety-like behavior in rat. J Behav Brain Sci 2013;3:519-602.

21. Santarelli L, Saxe M, Gross C, Surget A, Battaglia F, Dulawa S, et al. Requirement of hippocampal neurogenesis for the behavioral effects of antidepressants. Science 2003;301:805-9.

22. Graeber MB, Streit WJ. Microglia: Biology and pathology. Acta Neuropathol 2010;119:89-105.

23. Kazmi SM, Plante RK, Visconti V, Taylor GR, Zhou L, Lau CY. Suppression of NF kappa B activation and NF kappa B-dependent gene expression by tepoxalin, a dual inhibitor of cyclooxygenase and 5-lipoxygenase. J Cell Biochem 1995;57:299-310.

24. Tanuma N, Sakuma H, Sasaki A, Matsumoto Y. Chemokine expression by astrocytes plays a role in microglia/macrophage activation and subsequent neurodegeneration in secondary progressive multiple sclerosis. Acta Neuropathol 2006;112:195-204.

25. Sivakumar V, Foulds WS, Luu CD, Ling EA, Kaur C. Retinal ganglion cell death is induced by microglia derived pro-inflammatory cytokines in the hypoxic neonatal retina. J Pathol 2011;224:245-60.

26. Frakes AE, Ferraiuolo L, Haidet-Phillips AM, Schmelzer L, Braun L, Miranda CJ, et al. Microglia induce motor neuron death via the classical NF- $\mathrm{B}$ pathway in amyotrophic lateral sclerosis. Neuron 2014;81:1009-23.

27. Fan H, Zhang K, Shan L, Kuang F, Chen K, Zhu K, et al. Reactive astrocytes undergo M1 microglia/macrohpages-induced necroptosis in spinal cord injury. Mol Neurodegener 2016;11:14.

28. Webster CM, Hokari M, McManus A, Tang XN, Ma H, Kacimi R, et al. Microglial P2Y12 deficiency/inhibition protects against brain ischemia. PLoS One 2013;8:e70927.

29. Zhao CZ, Zhao B, Zhang XY, Huang XQ, Shi WZ, Liu HL, et al. Cysteinyl leukotriene receptor 2 is spatiotemporally involved in neuron injury, astrocytosis and microgliosis after focal cerebral ischemia in rats. Neuroscience 2011;189:1-1.

30. Pandey DK, Yadav SK, Mahesh R, Rajkumar R. Depression-like and anxiety-like behavioural aftermaths of impact accelerated traumatic brain injury in rats: A model of comorbid depression and anxiety. Behav Brain Res 2009;205:436-42.

31. Huang XJ, Zhang WP, Li CT, Shi WZ, Fang SH, Lu YB, et al. Activation of CysLT receptors induces astrocyte proliferation and death after oxygen-glucose deprivation. Glia 2008;56:27-37.

32. Lammers $\mathrm{CH}$, Schweitzer P, Facchinetti P, Arrang JM, Madamba SG, Siggins GR, et al. Arachidonate 5-lipoxygenase and its activating protein: prominent hippocampal expression and role in somatostatin signaling. J Neurochem 1996;66:147-52.

33. Raison CL, Lowry CA, Rook GA. Inflammation, sanitation, and consternation: Loss of contact with coevolved, tolerogenic microorganisms and the pathophysiology and treatment of major depression. Arch Gen Psychiatry 2010;67:1211-24.

34. Ul Ain Q, Greig NH, Nawaz MS, Rashid S, Kamal MA. Exploring $\mathrm{N}(1)$-p-fluorobenzyl-cymserine as an inhibitor of 5-lipoxygenase as a candidate for Type 2 diabetes and neurodegenerative disorder treatment. CNS Neurol Disord Drug Targets 2014;13:197-202.

35. Kawano T, Matsuse H, Kondo Y, Machida I, Saeki S, Tomari S, et al. Cysteinyl leukotrienes induce nuclear factor kappa $\mathrm{b}$ activation and RANTES production in a murine model of asthma. J Allergy Clin Immunol 2003;112:369-74.

36. Thompson C, Cloutier A, Bossé Y, Thivierge M, Gouill CL, Larivée P, et al. CysLT1 receptor engagement induces activator protein-1- and NF-kappaB-dependent IL-8 expression. Am J Respir Cell Mol Biol 2006;35:697-704.

37. Wang XY, Tang SS, Hu M, Long Y, Li YQ, Liao MX, et al. Leukotriene D4 induces amyloid- $\beta$ generation via CysLT(1)R-mediated NF- $\kappa$ B pathways in primary neurons. Neurochem Int 2013;62:340-7.

38. Sethi G, Sung B, Aggarwal BB. Nuclear factor-kappaB activation: From bench to bedside. Exp Biol Med (Maywood) 2008;233:21-31.

39. Ye SM, Johnson RW. Regulation of interleukin-6 gene expression in brain of aged mice by nuclear factor kappaB. J Neuroimmunol 2001; $117: 87-96$

40. Stadelmann C, Deckwerth TL, Srinivasan A, Bancher C, Brück W, Jellinger K, et al. Activation of caspase- 3 in single neurons and autophagic granules of granulovacuolar degeneration in Alzheimer's disease. Evidence for apoptotic cell death. Am J Pathol 1999;155:1459-66.

41. Lawrence T, Gilroy DW, Colville-Nash PR, Willoughby DA. Possible new role for NF-kappaB in the resolution of inflammation. Nat Med 2001;7:1291-7.

42. Rohn TT, Vyas V, Hernandez-Estrada T, Nichol KE, Christie LA, Head E. Lack of pathology in a triple transgenic mouse model of Alzheimer's disease after overexpression of the anti-apoptotic protein Bcl-2. J Neurosci 2008;28:3051-9.

43. Tusi SK, Ansari N, Amini M, Amirabad AD, Shafiee A, Khodagholi F. Attenuation of NF-kappaB and activation of Nrf2 signaling by 1,2,4-triazine derivatives, protects neuron-like PC12 cells against apoptosis. Apoptosis 2010;15:738-51.

44. Lepley RA, Fitzpatrick FA. 5-Lipoxygenase compartmentalization in granulocytic cells is modulated by an internal bipartite nuclear localizing sequence and nuclear factor kappa B complex formation. Arch Biochem Biophys 1998;356:71-6. 